\title{
Electron inelastic mean free path in water
}

Yesibolati, Murat Nulati; Lagana, Simone; Kadkhodazadeh, Shima; Mikkelsen, Esben Kirk; Sun, Hongyu; Kasama, Takeshi; Hansen, Ole; Zaluzec, Nestor J.; Mølhave, Kristian

\section{Published in:}

Nanoscale

Link to article, DOI:

10.1039/d0nr04352d

Publication date:

2020

Document Version

Peer reviewed version

Link back to DTU Orbit

Citation (APA):

Yesibolati, M. N., Lagana, S., Kadkhodazadeh, S., Mikkelsen, E. K., Sun, H., Kasama, T., Hansen, O., Zaluzec, N. J., \& Mølhave, K. (2020). Electron inelastic mean free path in water. Nanoscale, 12, 20649-20657. https://doi.org/10.1039/d0nr04352d

\section{General rights}

Copyright and moral rights for the publications made accessible in the public portal are retained by the authors and/or other copyright owners and it is a condition of accessing publications that users recognise and abide by the legal requirements associated with these rights.

- Users may download and print one copy of any publication from the public portal for the purpose of private study or research.

- You may not further distribute the material or use it for any profit-making activity or commercial gain

- You may freely distribute the URL identifying the publication in the public portal

If you believe that this document breaches copyright please contact us providing details, and we will remove access to the work immediately and investigate your claim 


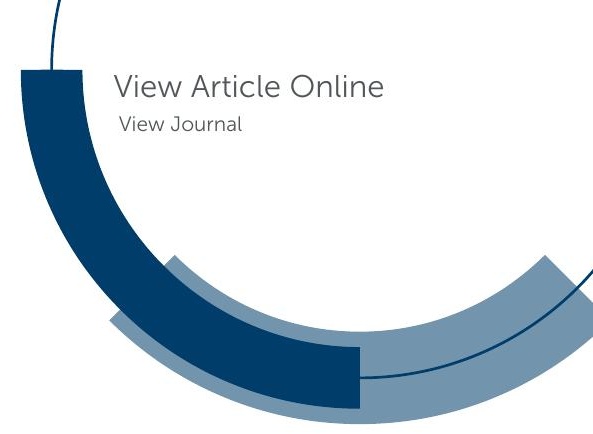

\section{Accepted Manuscript}

This article can be cited before page numbers have been issued, to do this please use: M. N. Yesibolati, S. Lagana, S. Kadkhodazadeh, E. K. Mikkelsen, H. Sun, O. Hansen, N. J. Zaluzec and K. Mølhave, Nanoscale, 2020, DOI: 10.1039/DONR04352D.

\section{Nanoscale}

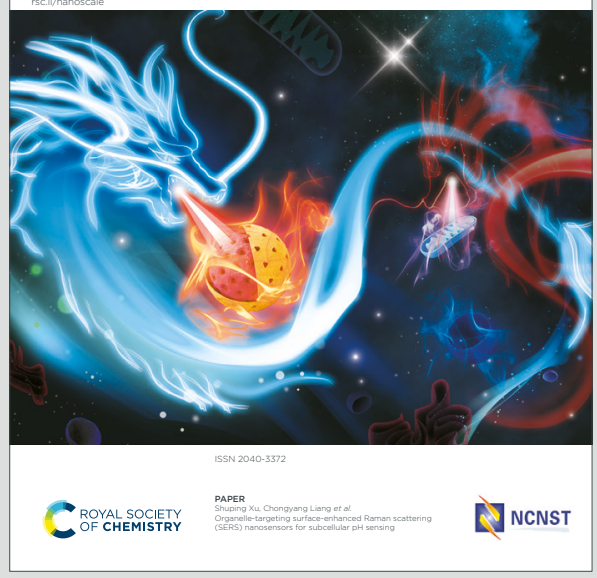

This is an Accepted Manuscript, which has been through the Royal Society of Chemistry peer review process and has been accepted for publication.

Accepted Manuscripts are published online shortly after acceptance, before technical editing, formatting and proof reading. Using this free service, authors can make their results available to the community, in citable form, before we publish the edited article. We will replace this Accepted Manuscript with the edited and formatted Advance Article as soon as it is available.

You can find more information about Accepted Manuscripts in the Information for Authors.

Please note that technical editing may introduce minor changes to the text and/or graphics, which may alter content. The journal's standard Terms \& Conditions and the Ethical guidelines still apply. In no event shall the Royal Society of Chemistry be held responsible for any errors or omissions in this Accepted Manuscript or any consequences arising from the use of any information it contains. 


\section{Journal Name}

ARTICLE TYPE

Cite this: DOI: $00.0000 / x x x x x x x x x x$

Received Date

Accepted Date

DOI: 00.0000/xxxxxxxxxx

Liquid phase transmission electron microscopy (LPTEM) is rapidly developing as a powerful tool for probing processes in liquid environments with close to atomic resolution. Knowledge of the water thickness is needed for reliable interpretation and modelling of analytical studies in LPTEM, and is particularly essential when using thin liquid layers, required for achieving the highest spatial resolutions. The log-ratio method in electron energy-loss spectroscopy (EELS) is often applied in TEM to quantify the sample thickness, which is measured relative to the inelastic mean free path $\left(\lambda_{\text {IMFP }}\right)$. However, $\lambda_{\text {IMFP }}$ itself is dependent on sample material, the electron energy, and the convergence and divergence angles of the microscope electron optics. Here, we present a detailed quantitative analysis of the $\lambda_{\text {IMFP }}$ of water as functions of the EELS collection angle $(\beta)$ at 120 $\mathrm{keV}$ and $300 \mathrm{keV}$ in a novel nanochannel liquid cell. We observe good agreement with earlier studies conducted on ice, but find that the most widely used theoretical models significantly underestimate $\lambda_{\text {IMFP }}$ of water. We determine an adjusted average energy-loss term $E_{m \text {,water, and characteristic }}$ scattering angle $\theta_{\mathrm{E} \text {, water }}$ that improve the accuracy. The results provide a comprehensive knowledge of the $\lambda_{\text {IMFP }}$ of water (or ice) for reliable interpretation and quantification of observations in LPTEM and cryo-TEM studies.

Liquid phase transmission electron microscopy (LPTEM) is emerging as a powerful method to investigate the evolution of materials' morphology and chemistry in-situ in their native liquid environment down to atomic resolution 12 . Advanced detectors ${ }^{3}$ and low dose ${ }^{4}$ imaging techniques have been used to reduce beam damage ${ }^{5}$ and artefacts $\sqrt{46}$, and have resulted in improved spatial and temporal resolutions 7 .

Liquid sample thickness is a crucial factor for interpreting physical and chemical processes observed in LPTEM, for instance mass transfer, sample-beam interactions 5 , nanoparticle/bubble growth and diffusion dynamics 911 , and electrochemical potential driven growth $12 \mid 13$. Additionally, reducing sample thickness is a significant factor for achieving higher spatial resolution in the LPTEM $^{14}$ and phase contrast imaging is only possible at ultra-thin liquid layer less than $\lambda_{\text {IMFP }} / 2$ 14|15 . The $\lambda_{\text {IMFP will also aid quan- }}$ titative analysis of High-Angle Annular Dark Field (HAADF) scanning TEM (STEM) imaging 16 and chemical analysis with elec-

$\ddagger$ These authors contributed equally to this work

$\dagger$ deceased 22.05.2019

*Corresponding to krmo@dtu.dk

${ }^{a}$ DTU Nanolab, National Centre for Nano Fabrication and Characterization, Technical University of Denmark, Building 307, $2800 \mathrm{Kgs}$. Lyngby, Denmark

${ }^{b}$ Argonne National Laboratory, Photon Sciences Division, 9700 S. Cass Avenue, Argonne,IL 60439 USA

$\dagger$ Electronic Supplementary Information (ESI) available: [details of any supplementary information available should be included here]. See DOI: 00.0000/00000000. tron energy-loss spectroscopy (EELS) 17 . Reducing liquid thickness is at times facilitated by means of creating radiolytic bubbles in the liquid cell 1819 , or by reducing the encapsulating membrane thickness and bulging using different liquid cell architectures 20 . However, such thin liquid layers can have vastly different mass transport mechanisms, which can potentially modify the kinetics and fluid dynamics in different liquid process, and can lead to misinterpretation of the results without knowing the liquid thickness. For example, in graphene trapped liquid blister cells 24 , one needs to know liquid thickness to estimate pressure in to better understand the reaction mechanisms $25[26$, or understand the degree of wall confinement in nanoparticle diffusion studies 912728 . Therefore, the actual liquid thickness present in liquid cell is a crucial factor for correctly interpreting many experiment results and modelling of analytical studies in LPTEM.

One can estimate liquid thickness by comparing electron beam currents with and without samples in TEM, at best with some $30 \%$ accuracy 2930 . However, electron energy loss spectroscopy (EELS) is the most frequently used method to calculate liquid sample thickness in TEM based on the log-ratio model that measures thickness relative to the inelastic mean free path $\left(\lambda_{\text {IMFP }}\right)^{31}$.

The EELS log-ratio model is based on Equation (1):

$$
\frac{t}{\lambda_{\mathrm{IMFP}}}=\ln \left(\frac{I_{\mathrm{t}}}{I_{0}}\right),
$$

where $\mathrm{t}$ is the sample thickness, $\lambda_{\text {IMFP }}$ is the inelastic mean free 
path, It is integrated area of the whole EELS spectrum, and $\mathrm{I}_{0}$ is the integrated area of the zero loss peak (ZLP) $\stackrel{31}{\text {. }}$

This relies on the $\lambda_{\text {IMFP }}$, whose value is, in general, estimated as in Equation 2232]33:

$$
\lambda_{\mathrm{IMFP}} \approx \frac{106 F E_{0}}{E_{\mathrm{m}} \ln \left(2 \beta E_{0} / E_{\mathrm{m}}\right)}, F=\frac{1+E_{0} / 1022}{\left(1+E_{0} / 511\right)^{2}}
$$

where $\mathrm{E}_{0}[\mathrm{keV}]$ is the electron energy, $\beta[\mathrm{mrad}]$ is the collection angle of the EELS spectrometer, $\mathrm{F}$ is the relativistic factor, and $\mathrm{E}_{\mathrm{m}}[\mathrm{eV}]$ is the average energy loss for the examined material. $E_{m}$ is in general dependent on the material refractive index and composition. However, $\mathrm{E}_{\mathrm{m}}$ is often calculated from Equation (3):

$$
E_{\mathrm{m}}=7.6 Z_{\text {eff }}^{0.36}
$$

which is an experimentally determined fit to results sourced from several solid materials, with $\mathrm{Z}_{\text {eff }}$ as the effective atomic number 3233 .

Little has been reported on $\lambda_{\text {IMFP }}$ in liquid water despite EELS having been applied in LPTEM ${ }^{17 / 34 / 35}$. Holtz et al. found $\lambda_{\text {IMFP }} \approx$ $106 \mathrm{~nm}$ at $200 \mathrm{keV}$ and $\beta>20$ mrad 17 , not matching expectations from Equation (2), in which they used a simple single-pole plasmon model assuming that the electrons in the fluid behave as free electrons. Tanase et al. have reported a single measurement $\lambda_{\text {IMFP }} \approx 330 \mathrm{~nm}$ for an unknown mixing ratio of water and ethanol of at $300 \mathrm{keV}$ and $\beta=9.6 \mathrm{mrad}^{23}$, almost 1.5 times that from Equation (2), maybe due to the addition of ethanol. However, without verifying Equation (2) and other $\mathrm{E}_{\mathrm{m}}$ models for liquids, relying on these models for calculating $\lambda_{\text {IMFP }}$ can lead to errors in estimating liquid thicknesses and subsequently, the interpretation of observations.

In this study, we have used a novel nanochannel liquid cell (Fig 1) that holds liquid layers with well-defined thicknesses, in order to carry out a detailed quantitative evaluation of the logratio EELS measurement of the $\lambda_{\text {IMFP }}$ of water and the encapsulating silicon nitride $\left(\mathrm{Si}_{3} \mathrm{~N}_{4}\right.$, and low stress silicon-rich $\left.\mathrm{SiN}_{\mathrm{x}}\right)$ membranes. The results are compared to two different models: the effective nuclear charge $\lambda_{\text {IMFP }}$ by Malis et al. presented in Equation (2) and (3) 3233 and the density dependent model by Iakoubovskii et al.as in Equation (4) and (5)

$$
\begin{gathered}
\lambda_{\mathrm{IMFP}} \approx \frac{200 F E_{0}}{11 \rho^{0.3}} / \ln \frac{1+\beta^{2} / \theta_{E}^{2}}{1+\beta^{2} / \theta_{c}^{2}} \\
\theta_{E}=5.5 \frac{\rho^{0.3}}{F E_{0}}
\end{gathered}
$$

in which $\rho$ is sample density $\left[\mathrm{gcm}^{-3}\right], \theta_{E}$ is the characteristic scattering angle, and $\theta_{c}$ is a saturation factor, and normally is set to $\theta_{c}=20[\mathrm{mrad}] 36$.

These two models are both used in the literature, but only occasionally compared, and there is no clear guideline for which one best describes the $\lambda_{\text {IMFP }}$ of water nor silicon nitride, which is the typical liquid encapsulation material in LPTEM. Our detailed study provides a fundamental reference methodology for future EELS and $\lambda_{\text {IMFP }}$ based studies in liquid samples. Additionally, the results are also highly relevant for cryo-TEM studies, in which vitrified ice thickness is a critical factor for obtaining better images 37 , as the results match to earlier ice measurements makes it reasonable to assume that these more extensive measurements on water can be transferred to apply to vitrified ice.

\section{Results and Discussion}

\section{The nanochannel Liquid Cell}

A conventional LPTEM cell uses two manually clamped microchips in which the liquid is enclosed between two thin ( $~$ $50 \mathrm{~nm}$ ) electron transparent silicon nitride membranes 38 , typically at least $50 \mu \mathrm{m}$ wide. Inside the TEM, the membranes bulge outwards, due to the ambient sample pressure difference with respect to the TEM vacuum chamber, resulting in liquid layer thickness variation over the field-of-view (FOV). In this case, the liquid layer thickness can reach up to a few micrometers in the middle of the membranes ${ }^{22}$, which significantly deteriorates the spatial resolution achievable in these regions of the membrane. In some cases, gaseous bubbles are generated during illumination with the electron beam, displacing the liquid to the bubbles periphery, and leaving a thin residual layer of liquid on the top and/or bottom membranes. This improves the spatial resolution, but similar to the membrane bulging, adds to the ambiguity about the true thickness of the liquid layer. Besides the poor spatial resolution in imaging of thick conventional liquid cells, the EELS signal in thicker liquids can also degrade, due to multiple scattering. Although EELS quantification in thick samples $\left(t / \lambda_{\text {IMFP }}>1\right)$ is possible in some cases ${ }^{39}$, and typically multiple plasmons dominate the spectra and can obscure information from other valence and core-loss signals ${ }^{40}$. Because of this, systems that allow control of the liquid thickness and quantification of the liquid thickness are needed to enable higher spatial resolution imaging, spectroscopic measurements, and complementary analytical studies.

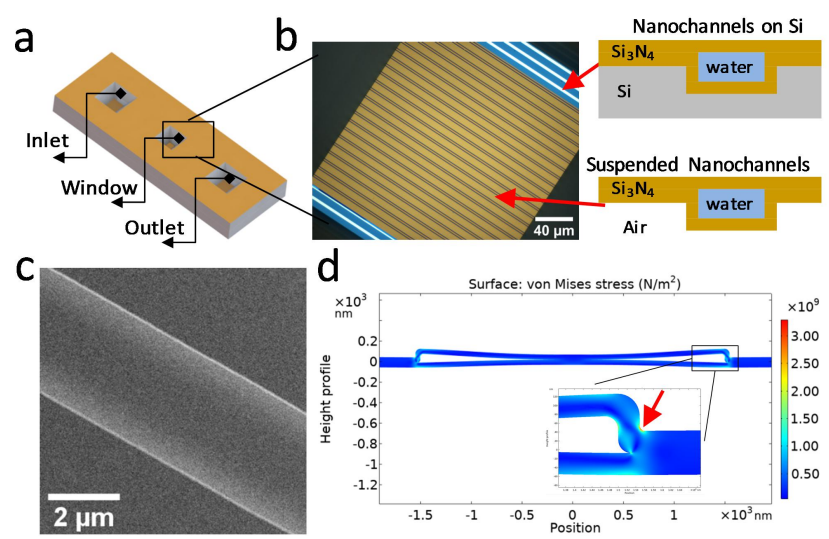

Fig. 1 The nanochannel liquid cell. a) A CAD drawing of the nanochannel liquid cell; it has one inlet and outlet with connected with nanochannels in-between as passing over a window region for imaging. b) A bright field optical microscopy (BFOM) image of the nanochannels in the window region. Due to light interference, the suspended nanochannel (brown) and the nanochannel on silicon (white) show different colours. c) A STEM HAADF image of a single nanochannel. The nanochannel is filled with liquid water, and bulges inward. d) A 2D COMSOL simulation shows the stress that a nanochannel experienced during the capillary filling. 
In liquid cell holders that employ manual clamping of the silicon nitride windows, reducing the bulging via shrinking the total size of the encapsulating membranes to a few $\mu \mathrm{m}$ is not practical, due to the stringent alignment tolerance of small windows. In this work, we have fabricated a nanochannel liquid cell (Fig 1 la-c) by bonding two $\mathrm{Si}_{3} \mathrm{~N}_{4}$ coated silicon wafers to encapsulate a channel system (see experimental section, and Figure $\left.\mathrm{S}^{\dagger}\right)^{21}$. The resulting bonded wafer architecture creates periodic connections between the top and bottom membranes (Fig 1 p), creating a large $(200 \mu \mathrm{m} \times 200 \mu \mathrm{m})$ window but with embedded 2.5-3.5 $\mu \mathrm{m}$ wide $\mathrm{Si}_{3} \mathrm{~N}_{4}$ nanochannels. This, in turn, results in the local top-tobottom bulge of the nanochannel being limited to a few nanometers ${ }^{41}$. The liquid layer thickness is then defined by the channel trench depth, which is formed during fabrication. The nanochannel system is hermetically sealed, until punctured for filling. This seals against external contamination making cleaning of the hydrophilic channels before use unnecessary.

The nanochannel liquid filling processes are described in Experimental section. The strong capillary force pulls the liquid into the nanochannels. The measured nanochannel height is $85 \pm 5$ $\mathrm{nm}$, as shown in the scanning electron microscopy (SEM) crosssection images in Figure $\mathrm{S}^{\dagger}$. We estimated the capillary filling pressure $\Delta p$ of the nanochannel with thickness $\mathrm{t} \sim 85 \mathrm{~nm}$ from the Young-Laplace equation $\Delta p=2 \cos \theta \gamma d^{-1}$ to be of the order $-15 \mathrm{bar}^{42}$ where $\gamma=0.073 \mathrm{Jm}^{-2}$ is the surface tension of water ${ }^{43}$, and assuming the contact angle $\theta=0^{\circ}$. The nanochannels become deformed due to the very high negative pressure developed behind the moving meniscus ${ }^{44}$. Using the COMSOL Multiphysics (B)simulation program (details can be found in Experimental section), we estimated the overall stress that the nanochannel experienced during filling by assuming a static pressure load (15 bar) on both inner sides of the suspended membranes. As shown in Fig $1 \mathrm{~d}$, the largest stress is concentrated near the outer corner of the nanochannel side wall (red arrow in Fig $1 \mathrm{~d}$ ), reaching a value of $3.3 \times 10^{9} \mathrm{Nm}^{-2}$ which is still below yield stress of $\mathrm{Si}_{3} \mathrm{~N}_{4}$, which if exceeded, would lead to formation of permanent cracks in the liquid cell 1556 . This stress is accommodated by plastic deformation of the nitride structure, which develops an inwards bow even under vacuum Fig 1 .

\section{$\lambda_{\text {IMFP }}$ of liquid water}

\section{Experimental Measurement of $\lambda_{\text {IMFP }}$}

The $\lambda_{\text {IMFP }}$ of liquid water and encapsulating stoichiometric silicon nitride $\left(\mathrm{Si}_{3} \mathrm{~N}_{4}\right)$ were experimentally measured using EELS with the microscope operated in STEM mode at electron energies $120 \mathrm{keV}$ and $300 \mathrm{keV}$, for various collection angles $\beta$ (see experimental section). The experiment data were acquired at convergence semi-angle $\alpha=4.9 \mathrm{mrad}$, and with all collection angles $\beta>=5$ mrad.The spectra were analysed using Hyperspy 47 , and additional post data analysis was conducted using custom python code.

Fig 2 p presents an annular dark field (ADF) image of a single nanochannel. This nanochannel was initially uniformly filled with water, as shown in Fig 11. However, a radiolysis induced gas bubble was generated during electron beam illumination. The gas bubble stabilized as a pocket along one side of the nanochannel

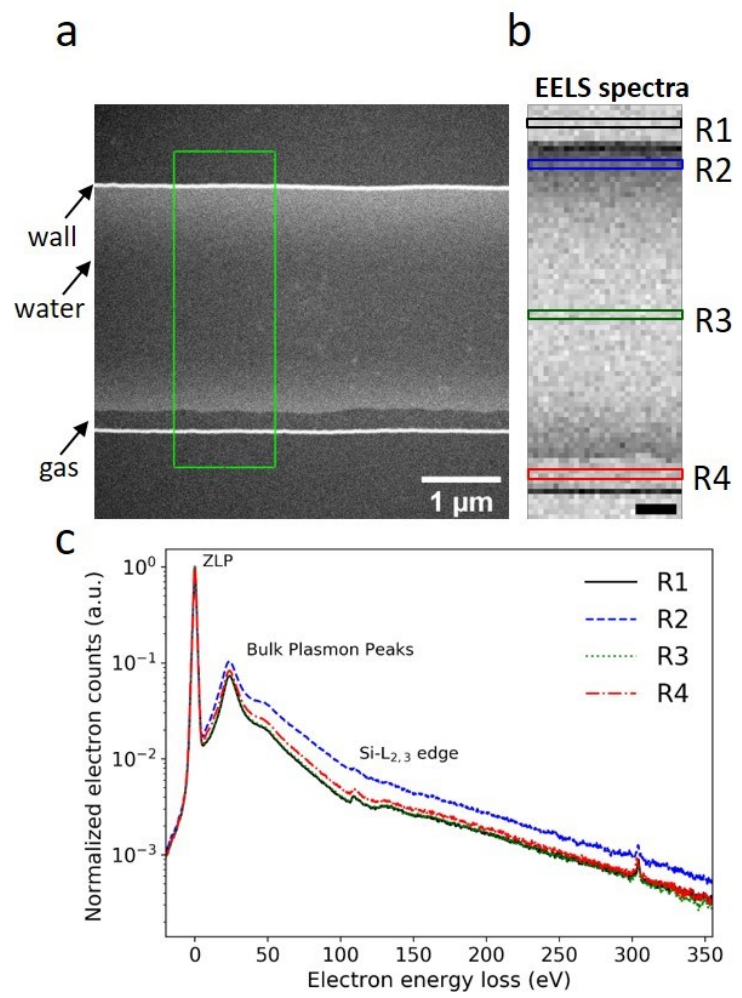

Fig. 2 STEM-EELS measurement of $\mathrm{Si}_{3} \mathrm{~N}_{4}$ and liquid water in a nanochannel liquid cell. a) An annular dark field (ADF) image of a single nanochannel; the green rectangle indicates the region where the EELS spectra in (b) was recorded from. The black arrow indicates the location of the gas bubble formed during beam irradiation. b) The EELS spectra of the nanochannel with liquid in between. Each pixel represents a spectrum. Pixel size is $\sim 40 \mathrm{~nm}$ and the scale bar is $400 \mathrm{~nm}$. c) spectra from the regions indicated in (b). R1: two bonded $\mathrm{Si}_{3} \mathrm{~N}_{4}$ membranes; $\mathrm{R} 2$ : two suspended $\mathrm{Si}_{3} \mathrm{~N}_{4}$ membranes with liquid water in between; R3: two collapsed $\mathrm{Si}_{3} \mathrm{~N}_{4}$ membranes assuming no liquid or ultra-thin water in between; R4: two suspended $\mathrm{Si}_{3} \mathrm{~N}_{4}$ membranes with radiolysis gas and thin water layers on both membranes. The peak around $303-304 \mathrm{eV}$ is a 'ghost zero loss peak ' artefact from the spectrometer readout system. It has only $0.1 \%$ in intensity compared to the ZLP and does not influence the analysis within error.

sidewall (indicated by the black arrow in Fig/2a). EELS spectrum $\sqrt[48]{ }$ were acquired from the marked area in Fig.2a pixel by pixel, and are shown in Fig 2 2 . The EELS spectra recorded in regions R1-R4 in Fig 2 2 are plotted in Fig 2 k, where the spectra in each pixel were summed along the direction parallel to the nanochannel side wall, and normalized with respect to the ZLP maximum intensity. Spectrum R3 shown in Fig 22 confirms the inward bulging of the nanochannel, as it is almost identical to the spectrum recorded from region R1. This indicates that there is at most an ultra-thin liquid layer present in region R3 which is at our detection limit. Region R2 is filled with water between two suspended $\mathrm{Si}_{3} \mathrm{~N}_{4}$ membranes, as can be confirmed by the increase in the energy-loss signal compared to regions R1 and R3. The spectrum from region R4 differs from R1 and R3. In region R4, gases released by radiolysis and residual thin liquid layers on top and bottom membranes contribute to the spectrum. The effects of radiolysis products in the water are estimated to be in the $\mathrm{mM}$ 

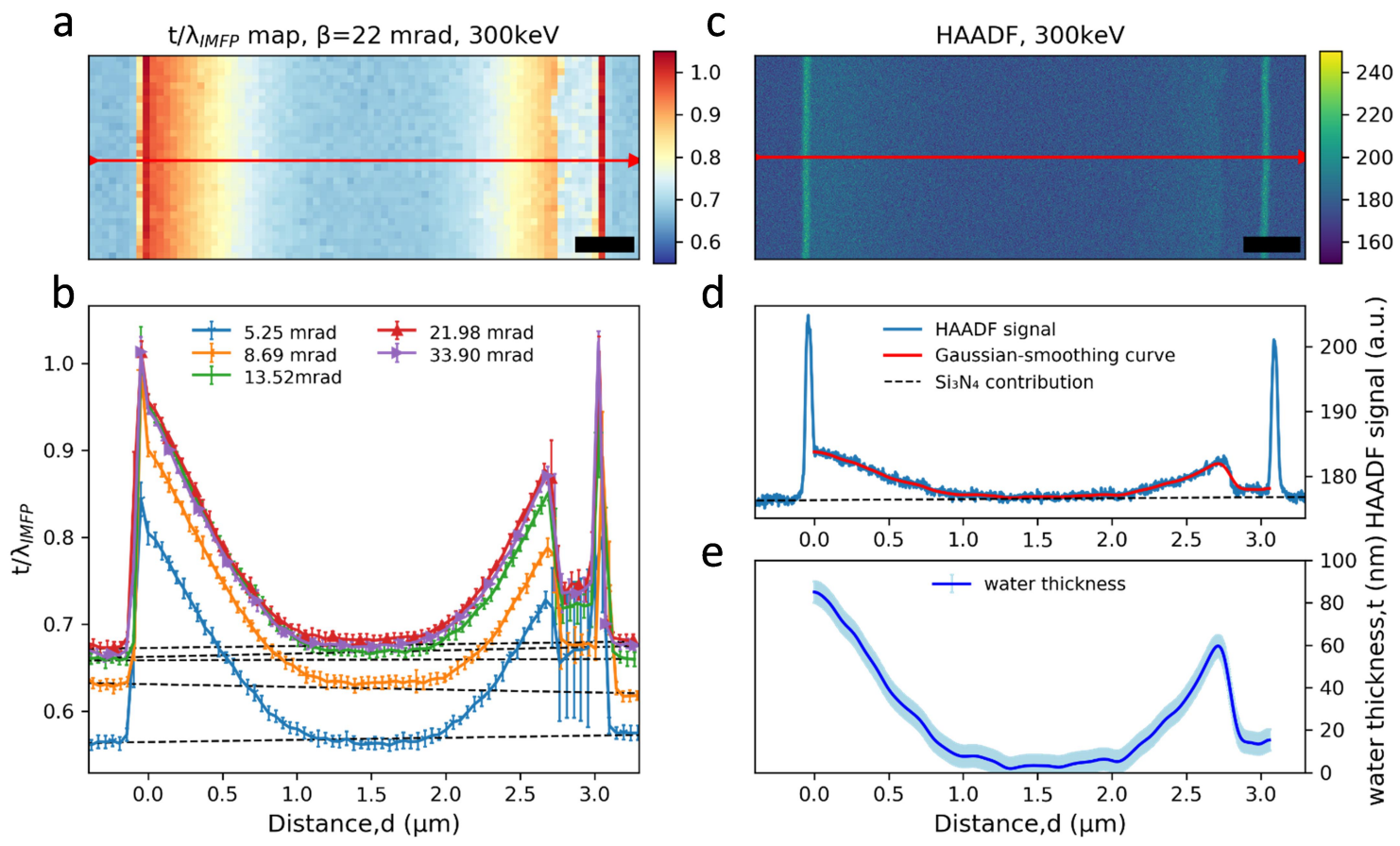

d

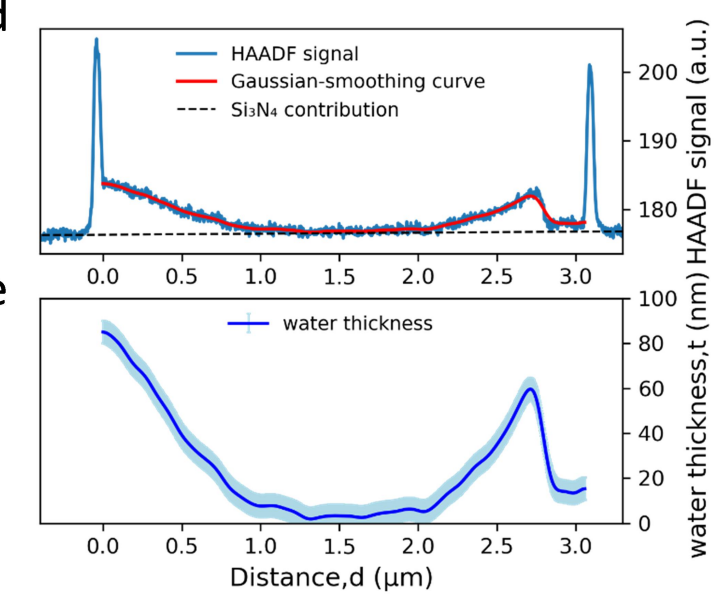

Fig. $3 \mathrm{t} / \lambda_{\text {IMFP }}$ and HAADF signal analysis in a nanochannel. a) $\mathrm{t} / \lambda_{\text {IMFP }}$ map of a nanochannel acquired at $300 \mathrm{keV}$ and with $\beta=22 \mathrm{mrad}$; $\mathrm{b}$ ) the $t / \lambda_{\text {IMFP }}$ plots along the arrow line shown in Fig 3 a recorded with different collection angles at $300 \mathrm{keV}$. The error bar is the standard deviation of $\mathrm{t} / \lambda_{\text {IMFP }}$ along the nanochannel sidewall. The dashed lines mark the average contribution from the $\mathrm{Si}_{3} \mathrm{~N}_{4}$ window in each case. c) a $\mathrm{HAADF}$ image of the nanochannel. The length of the scale bar is $400 \mathrm{~nm}$. d) Intensity of the HAADF signal along the arrow line shown in Fig 3 ;. e) The water thickness profile calculated from the HAADF signal along the arrow line, calibrated from the known channel height (SEM cross section image in Fig.S2). The error bar has contributions from both the standard deviation of the HAADF signal and the nanochannel thickness uncertainty. Distance $d=0$ is set to be the inner left-side of the nanochannel.

range $\mathrm{e}^{5}$ and neglected here as their concentrations are negligible compared to $56 \mathrm{M}$ water.

The relative thickness $t / \lambda_{\text {IMFP }}$ can be estimated from low-loss EELS spectra based on Equation (11). As an example, the $t / \lambda_{\text {IMFP }}$ map obtained from the spectrum image in Fig 2 , for $\beta=22 \mathrm{mrad}$ at electron energy $300 \mathrm{keV}$, is shown in Fig 33 . The $t / \lambda_{\text {IMFP }}$ maps of the same channel at different collection angles and electron energies are shown in Figure $S 3 \& S 4^{\dagger}$. The $t / \lambda_{\text {IMFP values for differ- }}$ ent collection angles measured at $300 \mathrm{keV}$ and averaged along the direction of the sidewall of the nanochannel are plotted in Fig $3 \mathrm{~b}$. As expected from Equations (1) and (2), $t / \lambda_{\text {IMFP }}$ increases with increasing $\beta$ in both the bonded $\mathrm{Si}_{3} \mathrm{~N}_{4}$ region and the water filled nanochannel region.

To calculate $\lambda_{\text {IMFP }}$, the nanochannel height is needed and was obtained from the SEM cross section images (Figure S2 ${ }^{\dagger}$ ). The liquid thickness, $t$, is equal to the nanochannel height near the sidewalls in the measurements, even when the suspended nanochannel has inward bulging (Fig_1F, Fig 3k). Considering that both the $\mathrm{Si}_{3} \mathrm{~N}_{4}$ and water are amorphous materials and the liquid cell is thin $\left(t / \lambda_{\text {IMFP }}<1\right)$, we can to a first approximation assume a linear relationship between the sample thickness and the HAADF image intensity $\frac{16 \sqrt{153}}{\text { in }} \mathrm{Fig} 3 \mathrm{~A}$. After subtracting the signal contribution from the $\mathrm{Si}_{3} \mathrm{~N}_{4}$, the measured channel height of $85 \mathrm{~nm}$ was assigned as the thickness of liquid water near the sidewall and extrapolated to the rest of the signal profile across the nanochannel to obtain the water thickness profile displayed in Fig 3. As shown in Fig 3, the liquid layer thickness decreases to below $10 \mathrm{~nm}$ in the middle of the nanochannel. This is a reasonable residual layer given the $3 \mathrm{~nm}$ RMS roughness of the $\mathrm{Si}_{3} \mathrm{~N}_{4}{ }^{21}$ and possibly the TEM vacuum causing an outwards bulging of the pressurized channel's top and bottom up to $10 \mathrm{~nm}^{41}$. It is worthwhile to note that in the bubble region the thickness of the thin liquid layer on the top or bottom membrane is also about 10 $\mathrm{nm}$ (neglecting any scattering in the gas), which might be used as an starting point estimate of cumulative liquid layer thickness in studies where a bubble is present between the membranes.

The $\mathrm{Si}_{3} \mathrm{~N}_{4}$ contribution (detailed in Figure $\mathrm{S} 5-\mathrm{S} 10^{\dagger}$ ) is first subtracted from the $t / \lambda_{\text {IMFP }}$ maps, giving solely the signal from liquid water. The resulting $t / \lambda_{\text {IMFP }}$ values are plotted as a function of distance relative to the inner sidewall of the nanochannels for different collection angles and for $300 \mathrm{keV}$ and $120 \mathrm{keV}$ electron beam energies (Fig 4 , b, respectively). $t / \lambda_{\text {IMFP }}$ of water shows a downward trend as a function of distance from the sidewall and towards the centre of the nanochannel. This is expected, as the nanochannel has an inward bow as explained earlier. Fig 4 r,d show the $\lambda_{\text {IMFP }}$ of liquid water at different collection angles and electron energies. At each energy they are fairly constant and consistent within error bars but with a slight tendency for increasing $\lambda_{\text {IMFP }}$ at thinner liquid thicknesses $(\mathrm{d}>0.5 \mu \mathrm{m})$. Given that the effect is small compared to the experimental errors, it is considered part of the noise, but if such an effect is present, it could be due to surface excitation and become important for measure- 

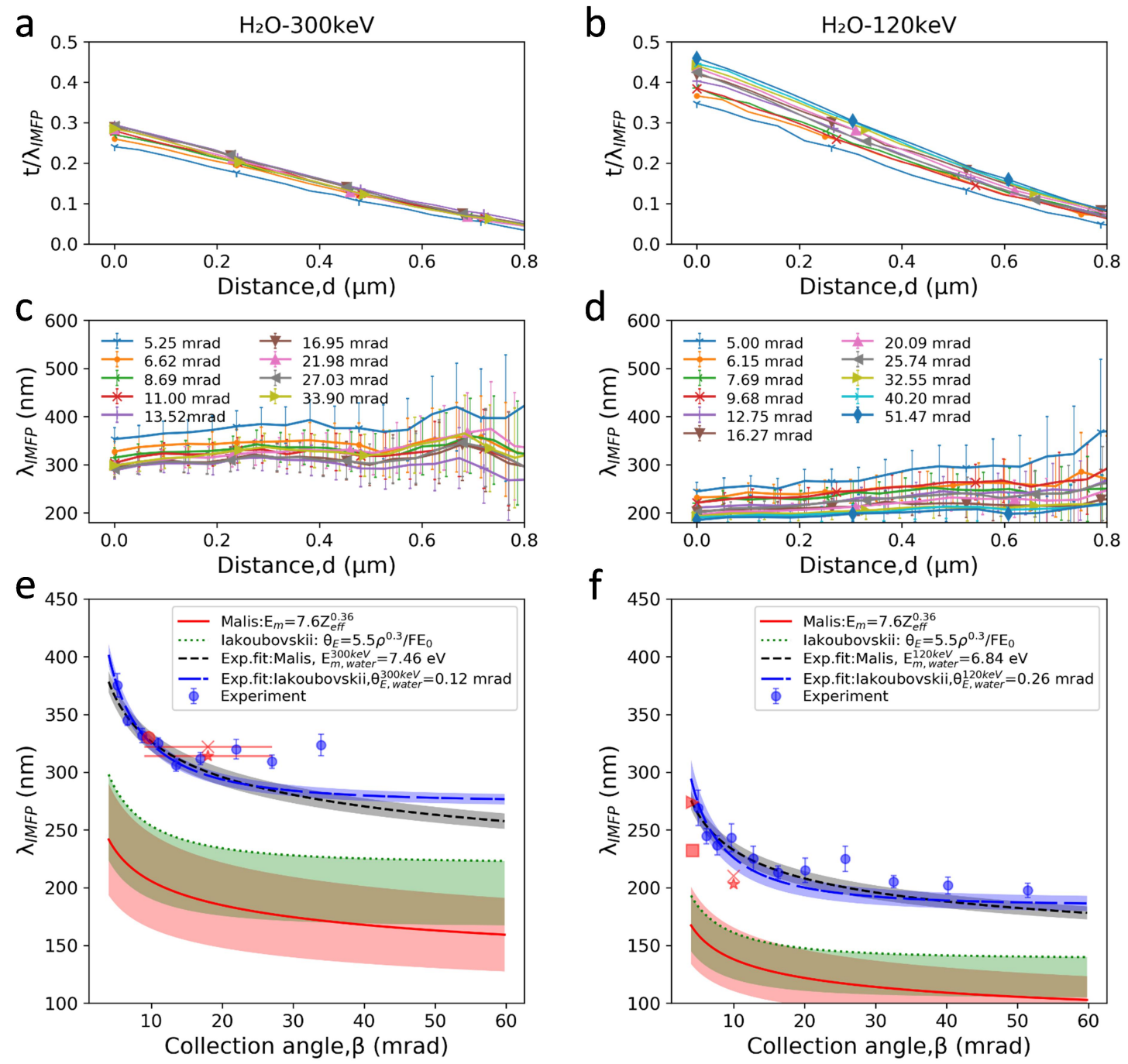

Fig. $4 \lambda_{\text {IMFP }}$ of liquid water. a) and b) The $t / \lambda_{\text {IMFP }}$ line plots across the nanochannel after subtracting the $\mathrm{Si}_{3} \mathrm{~N}_{4}$ contribution for 300 keV and $120 \mathrm{keV}$ beam energies, respectively. c) and d) The $\lambda_{\text {IMFP }}$ of liquid water at different positions across the nanochannel calculated by dividing the thickness profile of water estimated from HAADF images recorded at $300 \mathrm{keV}$ and $120 \mathrm{keV}$ by their corresponding $t / \lambda_{\text {IMFP }}$ profiles. The error bars have contribution from the uncertainty of the nanochannel thickness and the $t / \lambda_{\text {IMFP }}$ signal. a) has the same legend as $c$ ), and $b$ ) the same legend as d). e) and f) Our experimentally measured $\lambda_{\text {IMFP }}$ of liquid water vs. collection angle plotted alongside the models discussed in the text, and the values reported in the literature for water and ice. The values taken from the literature are: e) $\star$ : ice, M. J. Peet et al. (2019), with $\beta$ possibly in the range of $9<\beta<27 \mathrm{mrad}^{49}$; $\mathrm{X}$ : ice, W. J. Rice et al.(2018), object aperture diameter $(100 \mu \mathrm{m}) 37$; : water-ethanol mixture (of unknown mixing ratio), Tanase et al. (2015) 23! f) - ice, B. Feja et al.(1999) ${ }^{50}$; : ice, Egerton (1992), calculated by ref.50; X: ice, Egerton (1992), at 100 $\mathrm{keV} 51$; $\star$ : ice, R. Grimm et al. (1996) 52 . $\mathrm{Z}_{\text {eff }}\left(\mathrm{H}_{2} \mathrm{O}\right)=4.38$, and $\rho=1.00 \mathrm{gcm}^{-3}$ were used for the calculations in the two models, and the $\pm 20 \%$ accuracy (red) in the model Malis et al. and $25 \%$ overestimation (green) in the model labukouvskii et al. are plotted as the shaded regions in e,f. The error bars in experiment data are the standard deviation of the data in distance $0.05 \mu \mathrm{m}<\mathrm{d}<0.5 \mu \mathrm{m}$ shown in c,d. Only the experiment data with $\beta<20 \mathrm{mrad}$ were used for fitting. The shaded regions in exp. fit curves originate from the standard deviation of $E_{m}$ and $\theta_{E}$ as shown in Table 1 .

ments on ultrathin $(<10 \mathrm{~nm})$ liquid layers 3154

Considering the thickness uncertainty, signal to noise ratio (SNR) and possible effects from vicinity to the nanochannel side wall (Fig 44,d), the data from the distance $0.05 \mu \mathrm{m}<\mathrm{d}<0.5 \mu \mathrm{m}$ $\left(0.2<\mathrm{t} / \lambda_{\text {IMFP }}<0.5\right)$ was used to estimate the $\lambda_{\text {IMFP }}$ of liquid water at $120 \mathrm{keV}$ and $300 \mathrm{keV}$. Our experimentally determined $\lambda_{\text {IMFP }}$ for liquid water along with the reported values for liquid water and ice in other experimental studies, and the Malis et al. and Iabukouvskii et al. models are plotted in Fig 4 ,f.

As indicated in equation (1), the $t / \lambda_{\text {IMFP }}$ singles in the nanochannel region, are superimpose of a spatially varying $\mathrm{H}_{2} \mathrm{O}$ $\mathrm{t} / \lambda_{\text {IMFP }}$ signal that varies linearly with HAADF thickness and a constant silicon nitride $t / \lambda_{\text {IMFP }}$ signal. Therefore, a linear regression method $\sqrt{55-57}$ was used to separate the two signals, from which the $\lambda_{\text {IMFP }}$ of water and silicon nitride are achieved independently from the approach mentioned above giving results identical within error (Figure S11 ${ }^{\dagger}$ ).

Both our values and those reported elsewhere (ice ${ }^{\sqrt{37 / 49} 52}$ and water/ethanol mixture ${ }^{233}$ ) are significantly larger than those calculated: $60 \%-80 \%$ larger compared to the Malis model and 30\% 
- 50\% larger compared to the Iabukouvskii model. Even by considering the $\pm 20 \% \frac{32}{32}$ accuracy in the model by Malis et.al. and from $10 \% \sqrt{58}$ to $25 \% \sqrt{31}$ overestimation in the model Iabukouvskii et.al., the difference is still significant as shown in Fig 4 ,f.f.

It is important to note that, in the case of both models, $\mathrm{E}_{\mathrm{m}}$ (Equation (3) and $\theta_{\mathrm{E}}$ (Equation (5) are derived empirically from measurements on a limited group of solids and at specific electron beam energies ( $100 \mathrm{keV}$ by Malis et al. and $200 \mathrm{keV}$ by Iabukouvskii et al.). The Iabukouvskii model is known to overestimate sample thickness on average by $25 \% 31$, and possibly could be further improved by corrections ${ }^{58}$. Similarly, different expressions for $\mathrm{E}_{\mathrm{m}}$ at higher beam energies have been suggested also 59 .

It is worth noting that both the Malis and Iabukouvskis models make use of the Kramers-Kronig (K-K) model estimation of the absolute specimen thickness 31 , and Equation (2) and (4) are simplified from the K-K model assuming refractive index $\mathrm{n}$ 1, which is an important factor to consider for water/ice with refractive index $\mathrm{n}=1.33^{3136}$. However, by including a refractive index correction (Figure $\mathrm{S}^{\dagger} 2^{\dagger}$ ) as also discussed in an ice thickness study ${ }^{52}$, we do not find improved match to data, rather all predictions significantly deviated from the observations for both models.

No single model fits the measured values. Based on our measurements of $\lambda_{\text {IMFP }}$ in the range $\beta<20 \mathrm{mrad}$, we find that a simple fitted value of $E_{m}$ in the Malis model Equation (3) gives a reasonable fit as $E_{\text {m,water }}^{120 \mathrm{keV}}=6.84 \pm 0.25 \mathrm{eV}$ at $120 \mathrm{keV}$, and $E_{m, w a t e r}^{300 \mathrm{keV}}=7.48 \pm 0.22 \mathrm{eV}$ at $300 \mathrm{keV}$. Our $E_{m, w a t e r}^{120 \mathrm{keV}}$ matches the $E_{\text {m.ice }}^{100 \mathrm{keV}}=6.8 \mathrm{eV}$ value reported by Egerton for crystalline ice ${ }^{31 / 51}$. This is not surprising, given the small density and refractive index difference between water and ice, as vitreous ice has a volume density of $0.94 \mathrm{gcm}^{-3}$ at $84 \mathrm{~K}^{60061}$, and refractive index of $\mathrm{n}=1.31$ close to water's $1.33^{62}$. Therefore, our results are also relevant for cryo-TEM investigations, which employ vitreous ice. For the Iabukouvskii model, we find $\theta_{E, \text { water }}^{120 \mathrm{keV}}=0.26 \pm 0.04 \mathrm{mrad}$ and $\theta_{E, \text { water }}^{300 \mathrm{keV}}=0.12 \pm 0.01 \mathrm{mrad}$. These results are summarized in Table[1.

Table 1 Summary of the average energy-loss term $E_{m}$, and the characteristic scattering angle $\theta_{E}$ at different electron energies

\begin{tabular}{|c|c|c|c|c|}
\hline Material & Reference & $\begin{array}{l}\text { Electron } \\
\text { beam } \\
\text { energy } \\
(\mathrm{keV}) \\
\end{array}$ & $\begin{array}{l}\mathrm{E}_{\mathrm{m}} \\
(\mathrm{eV})\end{array}$ & $\begin{array}{l}\theta_{E} \\
\text { (mrad) }\end{array}$ \\
\hline \multirow{2}{*}{$\begin{array}{l}\text { Liquid } \\
\text { water }\end{array}$} & $\begin{array}{l}\text { Malis et al } 32 \sqrt[33]{ } \\
\text { Equation } 2 \& 3\end{array}$ & $\begin{array}{l}120 \\
300\end{array}$ & $\begin{array}{l}12.93 \\
12.93\end{array}$ & \\
\hline & $\begin{array}{l}\text { Iabukouvskii et al. }{ }^{36} \\
\text { Equation } 4 \text { \& }\end{array}$ & $\begin{array}{l}120 \\
300\end{array}$ & & $\begin{array}{l}0.06 \\
0.04 \\
\end{array}$ \\
\hline $\begin{array}{l}\text { Crystalline } \\
\text { ice }\end{array}$ & $\begin{array}{l}\text { Experiment } \\
\text { Egerton et al.3151 }\end{array}$ & 100 & 6.8 & \\
\hline $\begin{array}{l}\text { Liquid } \\
\text { water }\end{array}$ & $\begin{array}{l}\text { Experiment } \\
\text { in this work }\end{array}$ & $\begin{array}{l}120 \\
300\end{array}$ & $\begin{array}{l}6.84 \pm 0.25 \\
7.48 \pm 0.22\end{array}$ & $\begin{array}{l}0.26 \pm 0.04 \\
0.12 \pm 0.01\end{array}$ \\
\hline
\end{tabular}

In EELS and $t / \lambda_{\text {IMFP }}$ measurements, the specimen should be very thin, as deconvolution of multiple scattering signals become challenging in thick samples, but how thin is not unanimously defined. However,in practise, the plasmon peak should be no more than one-fifth the height of the zero-loss peak to accurately interpret the sample thickness ${ }^{\sqrt{63}}$, and preferably $\mathrm{t} / \lambda_{\text {IMFP }}<0.5-0.6 \frac{64}{}$, or up to a linearity until $t / \lambda_{\text {IMFP }}=2.5$ for ice ${ }^{50}$. Within uncertainty the $\lambda_{\text {IMFP }}$ is independent of thickness in this study in a range of $0.1<\mathrm{t} / \lambda_{\text {IMFP, }}$,water $<0.5$ for water(Fig, $4 k$, d), and $0.3<$ $\mathrm{t} / \lambda_{\text {IMFP,Si } \mathrm{N}_{4}}<1.0$ for silicon nitride (Figure S7 \& S10 ${ }^{\dagger}$ ), and up

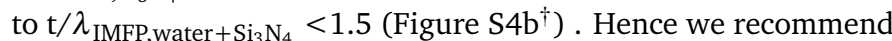
values from this work, $\mathrm{E}_{\mathrm{m}}, \theta_{E}$ and $\lambda_{\mathrm{IMFP}}$ can be used directly to calculate the liquid thickness up to $\mathrm{t} / \lambda_{\mathrm{IMFP}}=1.5$, and possibly can be extended to $t / \lambda_{\text {IMFP }}=2.550$, which corresponds to roughly $1 \mu \mathrm{m}$ liquid thickness (at $\beta=5 \mathrm{mrad}$ and $300 \mathrm{keV}$ ).

The result also indicate that careful validation of the $\lambda_{\text {IMFP }}$ should be considered in non-metal materials, as indicated in the original literature but today not always done in practise.

\section{Conclusions}

In summary, we used a novel nanochannel liquid cell that provides well defined liquid layer thickness, and quantified the $\lambda_{\text {IMFP }}$ of liquid water and silicon nitride $\left(\mathrm{Si}_{3} \mathrm{~N}_{4}\right.$, and $\left.\mathrm{SiN}_{\mathrm{x}}, \mathrm{ESI}^{\dagger}\right)$ over a range of different collection angles and for two electron energies (120 keV and $300 \mathrm{keV}$ ) and compared to the two main models in use today. In our evaluation, the $\lambda_{\text {IMFP }}$ of $\mathrm{Si}_{3} \mathrm{~N}_{4}$ and $\mathrm{SiN}_{\mathrm{x}}$ have the same $\lambda_{\text {IMFP }}$, and matches the Malis et al. model within uncertainty in the range $\beta<20 \mathrm{mrad}$ at higher electron energy (300 $\mathrm{keV}$ ), and matches both the Malis et al. and the Iabukouvskii et al. models at $120 \mathrm{keV}$. However, both models largely underestimate the $\lambda_{\text {IMFP }}$ of water compared to our experimental values, while the values reported in the literature for ice (single data points) are consistent with our results. A refractive index correction does not give a much better fit to data (Figure $S 12^{\dagger}$ ). The basis for discrepancies between our results and the two models are discussed, and the best fitted fixed values of $\mathrm{E}_{\mathrm{m}}$ and $\theta_{E}$ to the Malis and Iabokouvskii models are obtained. Based on these values, the absolute water or ice thickness in LPTEM and cryo-TEM studies can be estimated with high accuracy up to about $t / \lambda_{\text {IMFP }} \sim 2.5$ or about $1 \mu \mathrm{m}$ water thickness.

The results hence provide data and insight to the different approaches to $\lambda_{\text {IMFP }}$ calculations that may also be useful for gas cell and other liquid solutions. Given the low $t / \lambda_{\text {IMFP }}$ in the nanochannel architecture, it will be valuable for pursuing elemental characterization/quantification, such as oxygen and other species which are important for biological applications, and maybe even of light elements such as $\mathrm{H}_{2} \mathrm{~K}$-edge at $13 \mathrm{eV}$ in carefully designed experiments, which is also a radiolytic product in LPTEM 5

\section{Conflicts of interest}

There are no conflicts to declare.

\section{Author Contributions}

M.N. Yesibolati, S. Kadkhodazadeh, S. Lagana, T. Kasama and K. Mølhave designed and conducted the experiments; S. Laganá, and E. K. Mikkelsen fabricated the chips; M.N. Yesibolati made the TEM holder; H.Y. Sun helped with chip characterizations in TEM. M.N. Yesibolati, K. Mølhave, S. Kadkhodazadeh carried out data analysis and wrote the manuscript with corrections and revisions from N.J. Zaluzec, O. Hansen and H.Y. Sun . The manuscript was written through contributions of all authors. All authors have 
given approval to the final version of the manuscript.

\section{Acknowledgements}

The authors are grateful B. Wenzell for taking SEM cross section images; W. Huang for helping SEM sample preparation; J. Kling and A. Fuller for custom-made TEM holder inspection. B.D. Chang for helping with optical profilometer measurement, and A. Brostrøm for helping with python coding. We acknowledge financial support from the Danish Research Council for Technology and Production Case No. 12-126194. This work was supported in part by the Advanced Materials for Energy-Water Systems (AMEWS) Center, an Energy Frontier Research Center funded by the U.S. Department of Energy, Office of Science, Basic Energy Sciences.

\section{Experimental Section}

The nanochannel liquid cell microfabrication. The nanochannel devices were fabricated as depicted in Figure $S 1^{\dagger}$, by lithographically defining the channels on a double polished silicon wafer followed by transfer of the pattern into $\mathrm{Si}$ using a deep reactive ion etching system (DRIE). The channel depth is defined by the etching time. In order to remove any contamination, the wafers were cleaned in an RCA solution prior to Atomic Layer Deposition (ALD). A thin $\sim 3 \mathrm{~nm}$ layer of ALD $\mathrm{Al}_{2} \mathrm{O}_{3}$ was deposited on the channel wafer in order to improve the bonding adhesion. The wafers were annealed at $400{ }^{\circ} \mathrm{C}$ for 8 hours to enhance the bonding strength. Backside lithography is then applied to the un-patterned wafer, followed by etching in a $\mathrm{KOH} / \mathrm{H}_{2} \mathrm{O}$ solution at $80{ }^{\circ} \mathrm{C}$ of the fully bonded system in order to open in/outlet and release the middle membrane region. Once the $\mathrm{KOH}$ etch is completed the imaging membrane size was $200 \mu \mathrm{m} \times 200 \mu \mathrm{m}$. The final bonded chip systems have channels suspended in the middle membrane as depicted in Figure $\mathrm{S} 1 \mathrm{e}^{\dagger}$, and inlets are clean and sealed with suspended nitride membranes. After processing, chips are coated in protective resist and diced for further use.

Sample loading and sealing. Protective photoresist on chip was removed by placing chip into acetone and isopropanol baths. Both the in/outlet was protected by $\mathrm{Si}_{3} \mathrm{~N}_{4}$ membranes during cleaning. The membranes covering in/outlets were punctured mechanically before filling liquid. Filling of the nanofluidic chip was done by carefully placing a $1 \mu \mathrm{L}$ droplet of water solution on top of the inlet, and letting the capillary force draw the liquid into the nanochannels. The nanochannels were completely filled after the droplet was placed over the inlet. The high negative capillary pressure causes inwards bulging of the channel during filling. Plastic deformation of the nanochannel by the capillary pressure may cause some degree of permanent inwards bulging in the channel as mentioned in the paper (Fig 1 1 and 1c). After filling, the inlet and outlet were sealed with water-insoluble ultra-high vacuum (UHV) compatible epoxy (Epotek 77®). The nanochannel liquid cell was mounted in a custom built TEM holder after the epoxy had cured at room temperature.

COMSOL Multiphysics simulation. In order to assess the stress during liquid filling, Finite element analysis (FEA) was carried out using Comsol Multiphysics $₫$ (version 5.4). The model geom- etry was based on the nanochannel design. The calculus consists of Solid Mechanics module for a linear elastic material. We applied a static pressure load (15 bar) to the inner surfaces of the nanochannel that was needed to make the upper and lower part of the channel reach a collapsed state, and a stationary study was conducted.

STEM-EELS measurement. Before inserting the custom-built TEM holder, the nanochannel liquid cell was plasma cleaned ( (VAr: $\mathrm{VO}_{2}=4: 1$, at $4 \mathrm{mBar}$ and $100 \mathrm{~W}$ for 30 minutes) together with the custom-built holder to minimize any carbon contamination to the outer surfaces of the suspended membranes. The data were collected using an FEI Titan 80-300ST TEM operating at 120 $\mathrm{keV}$ and $300 \mathrm{keV}$ equipped with a Gatan Imaging Filter 865 Tridium. Pixel step size was around $20-40 \mathrm{~nm}$, and the pixel dwell time was around $0.05 \mathrm{sec}$. The collection angle $\beta$ was changed by adjusting the camera length, ranging from $5 \mathrm{mrad}<\beta<34$ $\operatorname{mrad}$ at $300 \mathrm{keV}$, and $5 \mathrm{mrad}<\beta<52 \mathrm{mrad}$ at $120 \mathrm{keV}$. The convergence semi-angle was $\alpha=4.9 \mathrm{mrad}$. The electron flux was between $40-60 e^{-} \AA^{-2} s^{-1}$.

We have restricted the study to thin samples to avoid complications due to multiple scattering. Moreover, elastic scattering can be an issue when using $\beta<\alpha$, or for crystalline samples if strong diffracted intensities occur within or outside the collection aperture ${ }^{32}$. However, in our case, $\beta>\alpha$ is chosen throughout, and the sample is liquid and amorphous so both these effects can be ruled out.

Thickness measurement. In order to take cross section images and obtain the nanochannel height and $\mathrm{Si}_{3} \mathrm{~N}_{4}$ thickness, we broke the chips used in this study, and immersed them into $15 \mathrm{wt} \% \mathrm{KOH}$ solution for 15 minutes at room temperature, and cleaned with DI water afterwards. FEI Analytical ESEM 250 was used to take the cross section images. Both the secondary and backscattered detectors were used.

The HAADF inner collection angles are: 99 mrad for $300 \mathrm{keV}$ and $125 \mathrm{mrad}$ for $120 \mathrm{keV}$. The absolute thickness value relies on the known water thickness at the nanochannel sidewall. The HAADF analysis is used to investigate if the $\lambda_{\text {IMFP }}$ depends on the water thickness, where 100 mrad collection angle ensures there is a linear relation ship between thickness and HAADF signal 16 153/65. Given there is no significant thickness dependence of the measured $\lambda_{\text {IMFP }}$ compared to the noise level, we allow the most reliable part of the HAADF measurements to be included in the dataset (up to $0.5 \mu \mathrm{m}$ from the sidewall).

Image analysis. The spectra were analyzed using Hyperspy 47 , and additional post data analysis conducted using custom python code including data/figure plots (Fig 3, Fig 4), data fitting (Fig,4).

\section{Notes and references}

1 F. M. Ross, Science, 2015, 350, aaa9886.

2 F. M. Ross, Liquid Cell Electron Microscopy, Cambridge University Press, Cambridge, 2016.

3 G. Marchello, C. De Pace, N. Wilkinson, L. Ruiz-Perez and G. Battaglia, eprint arXiv:1907.03348, 2019. 
4 T. H. Moser, H. Mehta, C. Park, R. T. Kelly, T. Shokuhfar and J. E. Evans, Science Advances, 2018, 4, eaaq1202.

5 N. M. Schneider, in Electron Beam Effects in Liquid Cell TEM and STEM, ed. F. M. Ross, Cambridge University Press, Cambridge, 2016, pp. 140-163.

6 T. J. Woehl, K. L. Jungjohann, J. E. Evans, I. Arslan, W. D. Ristenpart and N. D. Browning, Ultramicroscopy, 2013, 127, 53-63.

7 N. de Jonge, L. Houben, R. E. Dunin-Borkowski and F. M. Ross, Nature Reviews Materials, 2019, 4, 61-78.

8 H. Zheng, S. A. Claridge, A. M. Minor, A. P. Alivisatos and U. Dahmen, Nano Letters, 2009, 9, 2460-2465.

9 A. Verch, M. Pfaff and N. de Jonge, Langmuir, 2015, 31, 6956-6964.

10 J. Lu, Z. Aabdin, N. D. Loh, D. Bhattacharya and U. Mirsaidov, Nano Letters, 2014, 14, 2111-2115.

11 H. M. Zheng, S. A. Claridge, A. M. Minor, A. P. Alivisatos and U. Dahmen, Nano Letters, 2009, 9, 2460-2465.

12 E. R. White, S. B. Singer, V. Augustyn, W. A. Hubbard, M. Mecklenburg, B. Dunn and B. C. Regan, ACS Nano, 2012, 6, 6308-6317.

13 B. L. Mehdi, J. Qian, E. Nasybulin, C. Park, D. A. Welch, R. Faller, H. Mehta, W. A. Henderson, W. Xu, C. M. Wang, J. E. Evans, J. Liu, J. G. Zhang, K. T. Mueller and N. D. Browning, Nano Letters, 2015, 15, 2168-2173.

14 N. de Jonge, Ultramicroscopy, 2018, 187, 113-125.

15 M. N. Yesibolati, S. Laganà, H. Sun, M. Beleggia, S. M. Kathmann, T. Kasama and K. Mølhave, Physical Review Letters, 2020, 124, 065502.

16 W. Van den Broek, A. Rosenauer, B. Goris, G. T. Martinez, S. Bals, S. Van Aert and D. Van Dyck, Ultramicroscopy, 2012, 116, 8-12.

17 M. E. Holtz, Y. Yu, J. Gao, H. D. Abruña and D. A. Muller, Microscopy and Microanalysis, 2013, 19, 1027-1035.

18 G. Zhu, Y. Jiang, W. Huang, H. Zhang, F. Lin and C. Jin, Chemical Communications (Cambridge, United Kingdom), 2013, 49, 10944-10946.

19 X. Wang, J. Yang, C. M. Andrei, L. Soleymani and K. Grandfield, Communications Chemistry, 2018, 1, 80.

20 D. J. Kelly, M. Zhou, N. Clark, M. J. Hamer, E. A. Lewis, A. M. Rakowski, S. J. Haigh and R. V. Gorbachev, Nano Letters, 2018, 18, 1168-1174.

21 S. Lagana, E. K. Mikkelsen, R. Marie, O. Hansen and K. Molhave, Microelectronic Engineering, 2017, 176, 71-74.

22 E. Jensen and K. Mølhave, in Encapsulated Liquid Cells for Transmission Electron Microscopy, ed. F. M. Ross, Cambridge University Press, Cambridge, 2016, pp. 35-55.

23 M. Tanase, J. Winterstein, R. Sharma, V. Aksyuk, G. Holland and J. A. Liddle, Microscopy and microanalysis : the official journal of Microscopy Society of America, Microbeam Analysis Society, Microscopical Society of Canada, 2015, 21, 16291638.

24 J. M. Yuk, J. Park, P. Ercius, K. Kim, D. J. Hellebusch, M. F. Crommie, J. Y. Lee, A. Zettl and A. P. Alivisatos, Science, 2012,
$336,61$.

25 K. S. Vasu, E. Prestat, J. Abraham, J. Dix, R. J. Kashtiban, J. Beheshtian, J. Sloan, P. Carbone, M. Neek-Amal, S. J. Haigh, A. K. Geim and R. R. Nair, Nature Communications, 2016, 7, 12168.

26 S. M. Ghodsi, C. M. Megaridis, R. Shahbazian-Yassar and T. Shokuhfar, Small Methods, 2019, 3, 1900026.

27 J. W. Swan and J. F. Brady, Physics of Fluids, 2010, 22, year.

28 H. Faxen, PhD. Thesis, 1921.

29 N. de Jonge, N. D. Browning, J. E. Evans, S. W. Chee and F. M. Ross, in Resolution in Liquid Cell Experiments, ed. F. M. Ross, Cambridge University Press, Cambridge, 2016, pp. 164-188.

30 N. de Jonge, N. Poirier-Demers, H. Demers, D. B. Peckys and D. Drouin, Ultramicroscopy, 2010, 110, 1114-1119.

31 R. F. Egerton, in TEM Applications of EELS, ed. R. F. Egerton, Springer US, Boston, MA, 2011, pp. 293-397.

32 T. Malis, S. C. Cheng and R. F. Egerton, Journal of Electron Microscopy Technique, 1988, 8, 193-200.

33 R. F. Egerton and S. C. Cheng, Ultramicroscopy, 1987, 21 , 231-244.

34 K. Klein, N. de Jonge and I. Anderson, Microscopy and Microanalysis, 2011, 17, 780-781.

35 S. Keskin, P. Kunnas and N. de Jonge, Nano Letters, 2019, 19 , 4608-4613.

36 K. Iakoubovskii, K. Mitsuishi, Y. Nakayama and K. Furuya, Microscopy Research and Technique, 2008, 71, 626-631.

37 W. J. Rice, A. Cheng, A. J. Noble, E. T. Eng, L. Y. Kim, B. Carragher and C. S. Potter, Journal of Structural Biology, 2018, 204, 38-44.

38 N. de Jonge and F. M. Ross, Nature Nanotechnology, 2011, 6, 695.

39 K. J. Annand, I. MacLaren and M. Gass, Journal of Nuclear Materials, 2015, 465, 390 - 399.

40 R. R. Unocic, L. Baggetto, G. M. Veith, J. A. Aguiar, K. A. Unocic, R. L. Sacci, N. J. Dudney and K. L. More, Chemical Communications (Cambridge, United Kingdom), 2015, 51, 1637716380.

41 E. Jensen, A. Burrows and K. Mølhave, Microscopy and Microanalysis, 2014, 20, 445-451.

42 N. R. Tas, P. Mela, T. Kramer, J. W. Berenschot and A. van den Berg, Nano Letters, 2003, 3, 1537-1540.

43 Engineering ToolBox,Surface Tension of Water in contact with Air, 2004.

44 J. W. van Honschoten, M. Escalante, N. R. Tas, H. V. Jansen and M. Elwenspoek, Journal of Applied Physics, 2007, 101, 094310.

45 W.-H. Chuang, R. K. Fettig and R. Ghodssi, Journal of Micromechanics and Microengineering, 2007, 17, 938-944.

46 N. Azeggagh, Ph.D.Thesis, INSA de Lyon, 2015.

47 F. de la Peña, E. Prestat, V. T. Fauske, P. Burdet, P. Jokubauskas, M. Nord, T. Ostasevicius, K. E. MacArthur, M. Sarahan, D. N. Johnstone, J. Taillon, J. Lähnemann, V. Migunov, A. Eljarrat, J. Caron, T. Aarholt, S. Mazzucco, M. Walls, T. Slater, F. Winkler, pquinn dls, B. Martineau, G. Donval, 
R. McLeod, E. R. Hoglund, I. Alxneit, D. Lundeby, T. Henninen, L. F. Zagonel and A. Garmannslund, HyperSpy v1.5.1, 2019.

48 R. F. Egerton, in An Introduction to EELS, ed. R. F. Egerton, Springer US, Boston, MA, 2011, pp. 1-28.

49 M. J. Peet, R. Henderson and C. J. Russo, Ultramicroscopy, 2019, 203, 125-131.

50 B. Feja and U. Aebi, Journal of Microscopy, 1999, 193, 15-19.

51 R. Egerton, Proc. 50th Annual EMSA Meeting, 1992, p. pp. 1264-1265.

52 R. Grimm, D. Typke, M. Bärmann and W. Baumeister, Ultramicroscopy, 1996, 63, 169-179.

53 Z. Yu, D. A. Muller and J. Silcox, Ultramicroscopy, 2008, 108, 494-501.

54 P. E. Batson, Nature, 1993, 366, 727-728.

55 A. Varambhia, L. Jones, A. London, D. Ozkaya, P. D. Nellist and S. Lozano-Perez, Micron, 2018, 113, 69-82.

56 G.-z. Zhu and G. A. Botton, Microscopy and Microanalysis, 2014, 20, 649-657.

57 A. J. Craven, J. Bobynko, B. Sala and I. MacLaren, Ultramicroscopy, 2016, 170, 113-127.

58 H.-R. Zhang, R. F. Egerton and M. Malac, Micron, 2012, 43, $8-15$.

59 Q. Jin and D. Li, Microscopy and Microanalysis, 2006, 12, 1186-1187.

60 J. A. Ghormley and C. J. Hochanadel, Science, 1971, 171, 6264.

61 Y. Huang, X. Zhang, Z. Ma, W. Li, Y. Zhou, J. Zhou, W. Zheng and C. Q. Sun, Scientific Reports, 2013, 3, 3005.

62 E. D. Palik, Handbook of optical constants of solids, Academic Press, Orlando, 1985.

63 B. Fultz and J. Howe, in Inelastic Electron Scattering and Spectroscopy, ed. B. Fultz and J. Howe, Springer Berlin Heidelberg, Berlin, Heidelberg, 2013, pp. 181-236.

64 H. Meltzman, Y. Kauffmann, P. Thangadurai, M. Drozdov, M. Baram, D. Brandon and W. D. Kaplan, Journal of Microscopy, 2009, 236, 165-173.

65 D. O. Klenov and S. Stemmer, Ultramicroscopy, 2006, 106, 889-901. 